Dicle Tıp Dergisi / Dicle Medical Journal (2017) 44 (4) : 333-337

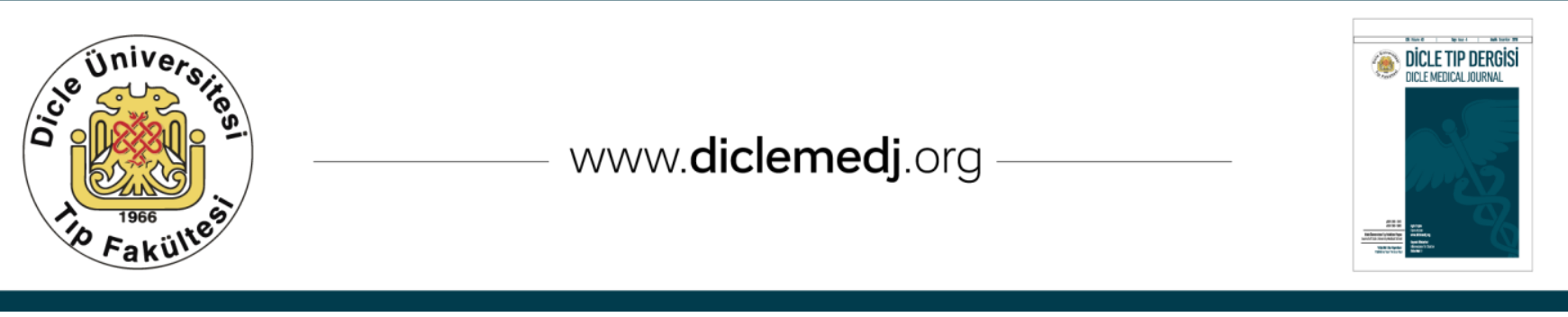

Özgün Araștırma / Original Article

\title{
Adneksiyal Torsiyonlu Hastaların Tanısında Mean Platelet Volümün Rolü Var mıdır?
}

\author{
Adnan İncebıyık ${ }^{1}$, Hacer Uyanıkoğlu² \\ 1 Harran Üniversitesi Tıp Fakültesi Kadın Hastalıkları ve Doğum AD, Șanlıurfa, Türkiye ORCID: 0000-0002-0500-4604 \\ 2 Harran Üniversitesi Tıp Fakültesi Kadın Hastalıkları ve Doğum AD, Şanlıurfa, Türkiye ORCID: 0000-0003-0316-4900
}

Geliş: 21.03.2017, Revizyon: 05.10.2017, Kabul Tarihi: 23.10.2017

\section{Özet}

Amaç: Bu çalışmada amacımız adneksiyal torsiyonlu hastalara tanı koymada mean platelet volümün (MPV) diagnostik değerini araștırmaktır.

Yöntemler: Çalışmamıza adneksiyal torsiyonlu toplam 21 hasta dahil edildi. Kontrol grubu olarak; rutin jinekolojik kontrol amacıyla polikliniğimize başvuran, kronik bir hastalığı olmayan ve ilaç kullanma hikâyesi bulunmayan 25 kadın dâhil edildi. Çalışmamızda trombosit fonksiyonunu etkileyebileceğinden dolayı anti-koagülan, non-steroid anti inflamatuar, oral kontraseptif kullanan ve kronik hastalığı olan kadınlar dâhil edilmedi. Tüm hastalarımızın ve kontrol grubu kadınların hemogramında lökosit, trombosit sayısı, nötrofil oranı ve MPV değerleri incelendi.

Bulgular: MPV değeri adneksiyal torsiyonlu hastalarda kontrol grubuna oranla daha düşük olarak bulundu $(6.23 \pm 1.14$ $\mathrm{fL}, 7.11 \pm 1.21 \mathrm{fL}$, sirasiyla). Adneksiyal torsiyon grubunda MPV değeri 18 hastada normalden düşük iken, kontrol grubunda ise 4 kişide normalden düşük bulundu. MPV oranında saptanan bu azalma adneksiyal torsiyonlu hasta grubu ile kontrol grubu kıyaslandığında istatiksel olarak anlamlı olarak saptandı $(\mathrm{p}<0.011)$. Trombosit sayısı ile MPV değeri arasında negatif bir korelasyon saptandı. Yani trombosit sayısı arttıkça MPV değerinin azaldığı görüldü $(\mathrm{p}=0.022, \mathrm{r}=-0.397)$.

Sonuç: Adneksiyal torsiyonlu hastaların tanı-tedavide olabilecek gecikme hastalığın morbiditesini artırır. Adneksiyal torsiyonlu hastalarda MPV değeri önemli ölçüde azaldığından dolayı, bu hastaların tanısında MPV değerinin bakılması tanı koyamaya yardımcı yararlı bir belirteç olabilir.

Anahtar kelimeler: Adneksiyal torsiyon, mean platelet volüm, trombosit, lökosit

DOI: $10.5798 /$ dicletip.362315

Yazışma Adresi / Correspondence: Adnan İncebıyık, Harran Üniversitesi Tıp Fakültesi Kadın Hastalıkları ve Doğum AD, Şanlıurfa, Türkiye e-mail: dr.aincebiyik@gmail.com 


\title{
Is there a role mean platelet volume in the diagnosis of patients with adnexal torsion?
}

\begin{abstract}
Objectives: Our aim in this study was to investigate whether mean platelet volume (MPV) value could be used as an early marker to predict adnexal torsion.

Methods: A total of 21 patients with adnexal torsion were retrospectively included in the study. The control group consisted of 25 women who applied to the clinic for a routine gynaecological checkup. Owing to the fact that it would affect thrombocyte function, women who have the following conditions were excluded from the study: women who were taking anticoagulant therapy, oral contraceptives, nonsteroid anti-inflammatory medications and who had chronic diseases. The leukocyte count, platelet count, neutrophil ratio and MPV values were collected from adnexal torsion and the control group.

Results: MPV values in patients with adnexal torsion were lower than those in the control group. While the MPV values of 18 patients in the adnexal torsion group were lower than normal, in the control group only 4 patients had values lower than normal. This reduction in MPV is statistically significant when the adnexal torsion group is compared with the control group $(\mathrm{p}<0.011)$. There was a negative correlation between platelet count and MPV values. That is to say, as the platelet count increased, MPV values decreased $(p=0.022, r=-0.397)$.

Conclusion: The morbidity increases with adnexal torsion when the delay in diagnosis and treatment. Since the MPV value was significantly decreased in patients with adnexal torsion, it may serve as an additional and valuable marker in the diagnosis of adnexal torsion.
\end{abstract}

Keywords: Adnexal torsion, mean platelet volume, platelet, leukocyte

\section{GíRiş}

Adneksiyal torsiyon; adneksiyal yapıların tuboovarian ligament merkezinde en az bir kez tam olarak rotasyonu sonucu oluşan akut batın tablosu olarak tanımlanır ${ }^{1}$. Torsiyon sonucunda arteriyal kan akımının azalması, ödem ve iskemi meydana gelir ${ }^{2}$. Torsiyonun devam etmesiyle arteriyal obstrüksiyona bağlı olarak dokuda nekroz gelişir ${ }^{3}$. Klinik olarak hastalarda şiddetli olabilen alt karın ağrısı, bulantı-kusma, alt batında hassasiyet, pelvik muayenede ele gelen kitle gibi akut batın tablosu ile kliniğe başvururlar ${ }^{2,4}$.

Tanıya yardımcl olması bakımından; ultrasonografi, doppler ultrasonografi ve manyetik rezonans görüntüleme kullanılabilmektedir-6. Ancak tanı yöntemleri içerisinde adneksiyal torsiyona özgü spesifik bir klinik yada laboratuvar bulgusu yoktur. Günümüzde laparoskopik gözlem adneksiyal torsiyon için en güvenilir yöntem olarak kabul edilmektedir. Ancak invaziv bir girişim olması; adneksiyal torsiyon açısından şüpheli olan klinik durumlarda liberal olarak kullanılmasını önlemektedir. $\mathrm{Bu}$ yüzden adneksiyal torsiyon için spesifik bir belirtece olan ihtiyaç halen devam etmektedir ${ }^{3,4}$.

Günümüzde trombositlerin sadece hemostazda görevli olmadığı aynı zamanda inflamatuar olayları da regüle ettiği düşünülmektedir $3,7,8$. Doku hasarı ve inflamatuar mediatörlerin salınımını takiben trombosit aktivasyonunda bir artış meydana gelmektedir9. Trombosit üretim, aktivasyon ve fonksiyonunda meydana gelen değişiklikler Mean Platelet Volum (MPV)'de değişikliklere neden olmaktadır. MPV; ülseratif kolit, romatoid artrit, ankilozan spondilit, akut pankreatit gibi hastalıklarda inflamatuar bir markır olarak çalışılmıștır. Ancak adneksiyal torsiyon olgularında MPV değişikliği ile ilgili yeteri kadar çalışma bulunmamaktadır ${ }^{3,8}$.

$\mathrm{Bu}$ yazıda amacımız enflamatuar ve doku hasarının beraber bulunduğu adneksiyal 
torsiyon olgularında MPV değerinin diagnostik önemini araştırmaktır.

\section{YÖNTEMLER}

Çalışmamız Üniversitesitemiz Tıp Fakültesi Kadın Hastalıkları ve Doğum Anabilim dalında Ocak 2011 ile 01 Temmuz 2015 tarihleri arasında adneksiyal torsiyon nedeniyle tedavi edilen toplam 21 hastanın retrospektif analizi olarak gerçekleştirildi. Çalışma planımız hastanemiz etik kurulu tarafından incelenerek onaylandl.

Hastanemiz elektronik kaylt sisteminden 01 Ocak 2011 ile 01 Temmuz 2015 tarihleri arasinda "International Classification of Diseases" hastalık kodlarına göre adneksiyal torsiyon (N83.5) tanısı ile jinekoloji servisine yatışı yapılan hastalar tarandı. Bu dönem içerisinde adneksiyal torsiyon nedeniyle yatışı yapılıp, adneksiyal torsiyon olduğu cerrahi ile doğrulanan toplam 21 hasta çalışmaya dâhil edildi.

Kontrol grubu olarak; rutin jinekolojik kontrol amacıyla polikliniğimize başvuran, kronik bir hastalığı olmayan ve ilaç kullanma hikâyesi bulunmayan 25 kadın dâhil edildi. Çalışmamızda trombosit fonksiyonunu etkileyebileceğinden antikoagülan tedavi alan, nonsteroid anti inflamatuar, oral kontraseptif kullanan ve kronik hastalığı olan kadınlar dâhil edilmedi.

Tüm hastalarımızın ve kontrol grubu kadınların hemogramlarında lökosit, trombosit sayısı, nötrofil oranı ve MPV değerleri incelendi. Çalışmaya dâhil edilen tüm katılımcıların kan değerleri Sysmex SE 9500 hematology analyzer (Roche Diagnostics, Mannheim, Germany) kullanılarak değerlendirildi. Gruplar arasındaki dağılımın benzer olması için gebe olan hastalar çalışmaya dâhil edilmedi.

İstatiksel analiz olarak SPSS 16.0 kullanıldı. Tüm veriler ortalama değer \pm standart deviasyon olarak hesaplandı. Verilerin dağılımında "Kolmogorov Smirnov" testi, sayısal değişkenler arasındaki farklar için "Independent Samples t-test", korelasyon için "Pearson" korelasyon testi kullanıldı. P değeri $<0,05$ olan sonuçlar istatiksel olarak anlamlı kabul edildi.

\section{BULGULAR}

Çalışmaya alınan adneksiyal torsiyonlu hastalarla kontrol grubunun demografik verileri ve laboratuvar sonuçları tablo 1'de özetlenmiştir. Yaş ve parite açısından her iki grup arasında anlamlı bir farklılık saptanmadı.

Tablo 1: Adneksiyal torsiyonlu hastalar ile kontrol grubunda yer alan kadınların demografik verileri ve laboratuvar sonuçları

\begin{tabular}{|c|c|c|c|}
\hline & $\begin{array}{c}\text { Adneksiyal } \\
\text { torsiyon } \\
\text { (Ortalama } \pm \text { SD, } \\
n=21 \text { ) }\end{array}$ & $\begin{array}{c}\text { Kontrol grubu } \\
\text { (Ortalama } \pm S D, \\
n=25)\end{array}$ & $\mathbf{P}$ \\
\hline Yaş & $27.05 \pm 3.14$ & $28.14 \pm 3.16$ & 0.816 \\
\hline Parite & $3.10 \pm 1.04$ & $3.14 \pm 1.03$ & 0.714 \\
\hline $\begin{array}{l}\text { Mean platelet } \\
\text { volume (fL) }\end{array}$ & $6.23 \pm 1.14$ & $7.11 \pm 1.21$ & 0.011 \\
\hline Nötrofil (\%) & $69.45 \pm 11.47$ & $61.78 \pm 5.28$ & 0.024 \\
\hline $\begin{array}{l}\text { Lökosit } \\
\left(\mathrm{mm}^{3} \mathrm{x} 10^{3}\right)^{\mathrm{a}}\end{array}$ & $13.25 \pm 4.36$ & $6.95 \pm 1.25$ & $<0.001$ \\
\hline $\begin{array}{l}\text { Trombosit } \\
\left(\mathrm{mm}^{3} \times 10^{3}\right)^{\underline{a}}\end{array}$ & $301.14 \pm 35.16$ & $297.25 \pm 34.16$ & 0.478 \\
\hline
\end{tabular}

Lökosit sayısı adneksiyal torsiyonlu hastalarda kontrol grubuna göre daha yüksek olarak saptandı. Lökosit sayısındaki bu artış adneksiyal torsiyonlu hasta grubu ile kontrol grubu kıyaslandığında istatiksel olarak anlamlı olarak tespit edildi $\left(13.25 \pm 4.36 \mathrm{~mm}^{3} \times 10^{3}\right.$, $\left.6.95 \pm 1.25 \mathrm{~mm}^{3} \times 10^{3} \mathrm{p}<0.001\right)$.

Nötrofil oranı adneksiyal torsiyonlu hastalarda kontrol grubuna göre yüksek olarak saptand. Nötrofil oranında bulunan bu yükselme adneksiyal torsiyonlu hasta grubu ile kontrol grubu kıyaslandığında istatiksel olarak anlamlı olarak bulundu (\%69.45 $\pm 11.47, \% 61.78 \pm 5.28$ $\mathrm{p}=0.024)$.

MPV değeri adneksiyal torsiyonlu hastalarda kontrol grubuna oranla daha düşük olarak bulundu. Adneksiyal torsiyon grubunda MPV değeri 18 hastada normalden düşük iken, 
kontrol grubunda ise 4 kişide normalden düşük bulundu. MPV oranında saptanan bu azalma adneksiyal torsiyonlu hasta grubu ile kontrol grubu kıyaslandığında istatiksel olarak anlamlı olarak saptand $16.23 \pm 1.14 \mathrm{fL}, 7.11 \pm 1.21 \mathrm{fL}$, $\mathrm{p}=0.011$ ).

Trombosit sayısı adneksiyal torsiyonlu hastalarda kontrol grubuna oranla daha yüksek saptand l fakat bu fark istatistiksel olarak anlaml değildi $\left(301.14 \pm 35.16 \mathrm{~mm}^{3} \times 10^{3}\right.$, $297.25 \pm 34.16 \mathrm{~mm}^{3} \times 10^{3}, \mathrm{p}=0.478$ ).

Adneksiyal torsiyonlu hasta grubunda trombosit sayısı ile MPV değeri arasında negatif bir korelasyon saptand. Yani trombosit sayısı arttıkça MPV değerinin azaldığ görüldü $(r=-0,397$, $\mathrm{p}=0.022$ ).

Çalışmamızda MPV değeri ile trombosit sayısı arasinda negatif anlamlı korelasyon saptanmasına rağmen lökosit ve nötrofil değerleri arasında anlamlı korelasyon saptanmadl.

\section{TARTIŞMA}

Adneksiyal torsiyon acil cerrahi gerektiren bir patoloji olup, tüm jinekolojik acil olgularının yaklaşık olarak \%2.5-7.4'ünü oluşturmaktadır ${ }^{2,10,11}$. Adneksiyal torsiyon olgularının yaklaşık olarak \%70-80'i reprodüktif yaş grubunda yer alan kadınlarda görülmektedir. Tanı ve tedavide olabilecek herhangi bir gecikme hem ovaryan fonksiyon kaybına hem de ileriki dönemde infertilite problemlerine yol açabilmektedir. Dolayısıyla erken tanı olanaklarının artması olası bu komplikasyonların önüne geçilmesi açısından son derece önemlidir ${ }^{2,3}$.

Adneksiyal torsiyonun spesifik bir klinik prezentasyonu olmaması diğer akut batın nedeni olan patolojilerden ayırımını güçleștirmektedir. Dolayısıyla abdomino-pelvik ağrı, bulantı, kusma, ateş gibi semptomlar bu acil klinik durumun ayırıcl tanısında yeterli olmamaktadır ${ }^{1,2,12}$. Tanıya yardımcı olması bakımından; ultrasonografi, doppler ultrasonografi ve manyetik rezonans görüntüleme kullanılabilmektedir ${ }^{13,14}$. Ancak belirtilen bu görüntüleme yöntemlerinin de kesin tanı konulmasında yararları sinırlı olmaktadir ${ }^{4,15}$.

MPV tam kan sayımı parametreleri arasında yer alan trombosit volümünün ölçülmesidir. Trombosit fonksiyonu ve aktivasyonunun bir göstergesi olduğu bilinmektedir ${ }^{16,17}$. Trombositlerde meydana gelen aktivasyon MPV'de değişikliklere neden olur. Crohn, ülseratif kolit, myokard enfarktüsü, romatoid artrit, unstabil anjina, preeklampsi gibi hastalıklarda oluşan MPV değişikliklerinin hastalık aktivasyonu ve inflamatuar olayın şiddetini yansıttığı ortaya konmuştur ${ }^{2,3,8}$.

Son literatür verileri incelendiğinde trombositlerin sadece hemostazda görevli olmadıkları, aynı zamanda vücutta meydana gelen inflamatuvar yanıtların regülasyonunda da görevli oldukları iddia edilmektedir. Doku hasarı ve sonrasında oluşan inflamatuvar sitokin üretimi trombosit üretim ve aktivasyonunda artışa neden olur. Trombosit üretiminde oluşan bu artışın da MPV değerinde düşüşe neden olduğu vurgulanmaktadır ${ }^{3}$. Bizim çalışmamızda da literatür bilgileriyle uyumlu olarak adneksiyal torsiyonlu hastalarda MPV değerinin kontrol grubuna göre istatiksel açıdan anlamlı bir şekilde düşük olduğu saptandı. Yine inlamatuar olayları tanımlamada kullanılan lökosit sayısında artış ve nötrofil oranında meydana gelen yükselmenin beklendiği gibi adneksiyal torsiyonlu hasta grubunda kontrol grubuna göre anlamlı oranda yüksek olduğu bulundu.

Çalışmamızın çeşitli sınırlamalara sahip olduğu söylenebilir. Bunlar arasında çalışmanın tek merkezli olarak yürütülmesi, çalışmaya dâhil edilen adenksiyal torsiyonlu hasta sayısının az olması, MPV ölçümünde tek yöntem kullanılması ve çalışmanın retrospektif olarak yapılması sayılabilir. 
Sonuç olarak adneksiyal torsiyon olgularında erken tanı ve hızlı cerrahi müdahale over fonksiyonlarının korunması açısından hayati derecede önemlidir. Bu amaçla ilk kullanılacak yöntem ultrasonografi ve doppler ultrasonografik inceleme olmakla beraber bu tanı yöntemlerinin yeterli olamayabileceği unutulmamalıdır. Dolayısıyla adneksiyal torsiyon olduğundan şüphelenilen hastalarda rutin hemogram parametrelerinden biri olan MPV değerinin irdelenmesi kolay ve maliyet açısından etkin bir yöntem olabilir.

Çıkar Çatışması Beyanı: Yazarlar çıkar çatışması olmadığını bildirmişlerdir.

Finansal Destek: Bu çalışma her hangi bir fon tarafından desteklenmemiştir.

Declaration of Conflicting Interests: The authors declare that they have no conflict of interest.

Financial Disclosure: No financial support was received.

\section{KAYNAKLAR}

1. Incebiyik A, Camuzcuoglu A, Hilali NG, Vural M, Camuzcuoglu H. Plasma D-dimer level in the diagnosis of adnexal torsion. J Matern Fetal Neonatal Med. 2015;28:1073-6.

2. Koleli I. Mean Platelet Volume in Early Diagnosis of Adnexal Torsion. Balkan Med J. 2015;32:410-3.

3. Incebiyik A, Seker A, Vural M, Hilali NG, Camuzcuoglu A, Camuzcuoglu H. May mean platelet volume levels be a predictor in the diagnosis of pelvic inflammatory disease? Wien Klin Wochenschr. 2014;126:422-6.

4. Polat M, Şenol T, İncebıyık A, Ozkaya E, Sanverdi I, Bostanci E, et al. Retrospective analysis of 14 patients who managed for adnexal torsion during pregnancy. Dicle Med J. 2015;42:490-4.
5. Beranger-Gibert S, Sakly $H$, Ballester $M$, et al. Diagnostic Value of MR Imaging in the Diagnosis of Adnexal Torsion. Radiol 2015;1:261-3.

6. Smorgick N, Melcer Y, Sarig-Meth T, Maymon R, Vaknin Z, Pansky M. High risk of recurrent torsion in premenarchal girls with torsion of normal adnexa. Fertil Steril. 2016;105:1561-5.

7. Jaiyeoba 0, Soper DE. A practical approach to the diagnosis of pelvic inflammatory disease. Infect Dis Obstet Gynecol. 2011;20:753-7.

8. Seker A, Incebiyik A, Kucuk A, Terzi A, Yucel Y, Ciftci R, et al. Mean platelet volume in patients with acute and chronic cholecystitis. Acta Med Mediter. 2013;29:5159.

9. Beyazit Y, Sayilir A, Torun S, Suvak B, Yesil Y, Purnak T, et al. Mean platelet volume as an indicator of disease severity in patients with acute pancreatitis. Clin Res Hepatol Gastroenterol. 2012;36:162-8.

10. Spinelli C, Piscioneri J, Strambi S. Adnexal torsion in adolescents: update and review of the literature. Cur Op Obstet Gynecol. 2015;27:320-5.

11. Vijayalakshmi K, Reddy GM, Subbiah VN, Sathiya S, Arjun B. Clinico-pathological profile of adnexal torsion cases: a retrospective analysis from a tertiary care teaching hospital. J Clin Diagn Res. 2014;8:4-7.

12. Hatipoglu S, Hatipoglu F, Abdullayev R. Acute right lower abdominal pain in women of reproductive age: clinical clues. World J Gastroenterol. 2014;20:4043-9.

13. Chang S-D, Yen C-F, Lo L-M, Lee C-L, Liang C-C. Surgical intervention for maternal ovarian torsion in pregnancy. Taiwan J Obstet Gynecol. 2011;50:458-62.

14. Peña JE, Ufberg D, Cooney N, Denis AL. Usefulness of Doppler sonography in the diagnosis of ovarian torsion. Ferti Steril. 2000;73:1047-50.

15. Evsen MS, Soydinç HE. Emergent gynecological operations: A report of 105 cases. J Clin Exp Invest 2010;1:12-15.

16. Yenigün EC, Okyay GU, Pirpir A, Hondur A, Yildirim IS. Increased mean platelet volume in type 2 diabetes mellitus. Dicle Med J 2014; 41:17-22.

17. Şahpaz F, Ulutaş KT. Assessment of mean platelet volume in type 2 diabetics receiving insulin or oral antidiabetic agents. Dicle Med J 2015;42:399-403. 